\title{
IRREDUCIBLE ANTERIOR DISLOCATION OF THE SHOULDER
}

\author{
S. J. S. LAm, London, ENGLAND
}

From the Department of Orthopaedic Surgery, Guy's Hospital, London

Much has been written on anterior dislocation of the shoulder in which stable reduction could not be achieved by manipulation under anaesthesia. However, all published reports on this subject are concerned with old dislocations (Corlette 1927; Doege 1929; Johnson 1931; Cubbins, Callahan and Scuderi 1934; Bennett 1936); dislocations associated with fractures around the shoulder (Doege 1929, Herbert 1946, Platzgummer 1953); or unstable reduction (Doege 1929, Razemon 1961, Rowe 1962). Failure to reduce an uncomplicated anterior

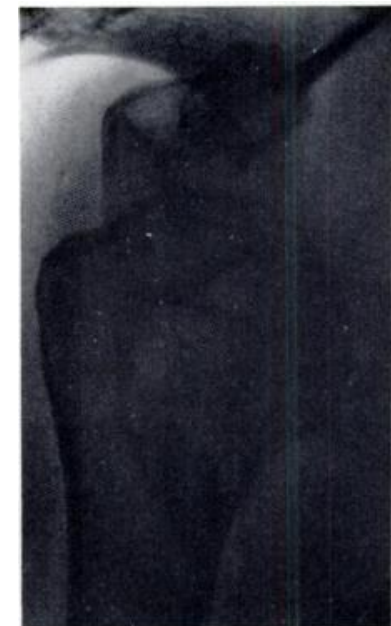

FIG. 1

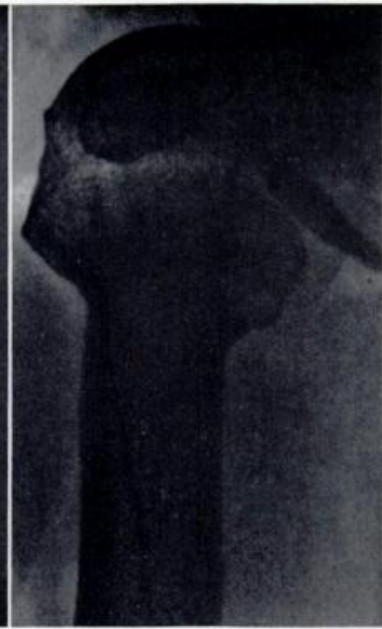

Fig. 2

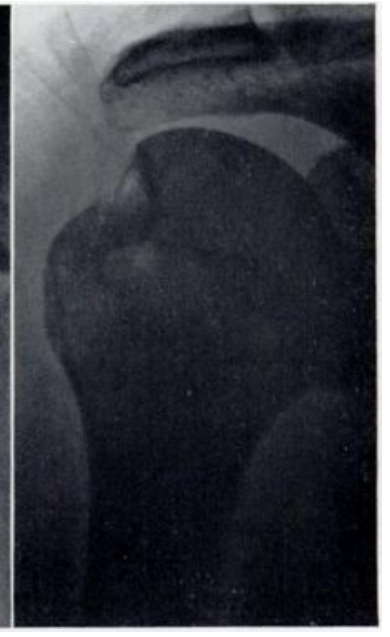

FiG. 3

Figure 1-Antero-posterior radiograph of the dislocation. Figure 2-Axial radiograph of the dislocation, showing impaction of the defect in the head of the humerus on the anterior glenoid margin. Figure 3-Antero-posterior radiograph after operation. The humeral head defect can be seen at the supero-lateral aspect of the head.

dislocation of the shoulder by manipulation under anaesthesia soon after injury must be extremely uncommon, and no reported case can be found.

This report describes such a case and explains its mechanism.

\section{CASE REPORT}

A man of fifty-four was injured in a road accident and sustained anterior dislocation of the right shoulder. He also had a closed comminuted fracture of the left femoral shaft. Neither was complicated by nerve or vascular injury.

Three hours after admission to hospital the shoulder was manipulated under halothane anaesthesia. Despite all attempts the dislocation could not be reduced, and the humeral head remained firmly impacted in its dislocated position. In the radiographs it appeared firmly impacted on the anterior margin of the glenoid (Figs. 1 and 2). Closed reduction was abandoned and open reduction was undertaken the following day.

Operation-The shoulder was explored through the anterior delto-pectoral approach. The subscapularis muscle was found stretched tightly across the front of the humeral head, which could not be moved by manipulation of the arm until the tension across the front of the joint 
had been relieved by division of subscapularis. Once this had been done the humeral head could be lifted off the anterior margin of the glenoid and reduced easily by medial rotation of the humerus. There was a corresponding large defect in the posterior part of the head of the humerus, and the ragged and torn labrum was completely detached from the glenoid margin. Lateral rotation of the humerus then caused redislocation and the defect in the humeral head engaged and locked across the anterior margin of the glenoid. After reduction of the shoulder the frayed segment of labrum was excised and a Putti-Platt repair was done, maintaining the humerus in medial rotation.

Four months later the shoulder remained reduced and stable, with 120 degrees of flexion and 90 degrees of abduction.

\section{COMMENT}

It seems evident that closed reduction failed in this case because the defect in the humeral head was firmly wedged on the anterior margin of the glenoid, and also because it was not possible to disimpact it due to the tightness of the subscapularis muscle stretched across its anterior aspect. The pathological features seen at operation after this single injury were similar to those commonly associated with recurrent dislocations of the shoulder. Figure 3 shows the antero-posterior radiograph taken two days after operation, and the defect is apparent at the supero-lateral corner of the humeral head. It was considered unjustifiable to attempt an axial radiograph with the arm laterally rotated soon after operation just to demonstrate the defect more clearly. The fact that Figure 2 demonstrates true impaction of the humeral head across the glenoid margin, and not merely superimposition, is shown by the complete break in continuity in the posterior contour of the humeral head across the area of impaction.

I am very grateful to $\mathrm{Mr}$ T. T. Stamm for permitting me to publish details of this case, and to Mr J. S. Batchelor for his helpful comments.

\section{REFERENCES}

Bennett, G. E. (1936): Old Dislocations of the Shoulder. Journal of Bone and Joint Surgery, $18,594$.

CoRlette, C. E. (1927): Open Reduction of Sub-coracoid Dislocation of Shoulder Nine Weeks after Injury, Followed by Complete Recovery. Medical Journal of Australia, ii, 514.

Cubbins, W. R., Callahan, J. J., and Scuderi, C. S. (1934): The Reduction of Old or Irreducible Dislocations of the Shoulder Joint. Surgery, Gynecology and Obstetrics, 58, 129.

DoEge, K. W. (1929): Irreducible Shoulder Joint Dislocations; with Report of Case. Journal-Lancet, 49, 191. Herbert, J. J. (1946): Luxation irréductible d'emblée de l'épaule et fractures tubérositaires. Revue d'Orthopédie, 32, 63.

Johnson, H. F. (1931): Unreduced Dislocations of the Shoulder. Nebraska State Medical Journal, 16, 220.

Platzgummer, H. (1953): Zur blutigen Behandlung irreponibler und veralteter Luxationen und Luxationsfrakturen des Schultergelenkes. Archiv für orthopädische und Unfall-Chirurgie, 45, 514.

Razemon, J. P. (1961): Luxations incoercibles de l'épaule. Acta Orthopaedica Belgica, 27, 239.

Rowe, C. R. (1962): Acute and Recurrent Dislocations of the Shoulder. Journal of Bone and Joint Surgery, 44-A, 998. 